\title{
Improvement of energy efficiency and quality of street lighting in South Italy as an action of Sustainable Energy Action Plans. The case study of Comiso (RG).
}

\author{
M. Beccali* \\ DEIM-Dipartimento dell'Energia dell'Ingegneria dell'informazione e dei Modelli matematici \\ Università degli Studi di Palermo, Viale delle Scienze, Bldg. 9, 90128, Palermo, Italy \\ e-mail: marco.beccali@dream.unipa.it \\ M. Bonomolo, G. Ciulla, A. Galatioto, V. Lo Brano \\ DEIM-Dipartimento dell'Energia dell'Ingegneria dell'informazione e dei Modelli matematici \\ Università degli Studi di Palermo, Viale delle Scienze, Bldg. 9, 90128, Palermo, Italy \\ e-mail: marinabonomolo@gmail.com \\ e-mail: ciullaina@dream.unipa.it \\ e-mail: alessandra.galatioto@dream.unipa.it \\ e-mail: lobrano@dream.unipa.it \\ G. Saddemi \\ Ufficio Tecnico del Comune di Comiso \\ Comune di Comiso (RG), Italy \\ e-mail: pipposaddemi@virgilio.it
}

\begin{abstract}
Existing street lighting systems in most of Sicilian cities are often inappropriate due to the obsolescence of light sources and luminaires and of unsuitable light control systems unable to provide efficient on-off and dimming strategies. Improvement of energy efficiency in street lighting systems can be one of the key actions adopted by Public Administration in developing Sustainable Energy Action Plan in the framework of the "Covenant of Majors" activities. As a task of FACTOR 20 project a set of planning options have been analysed and proposed for Sicilian cities. Particularly, street lighting efficiency projects have been studied for representative case studies. A detailed survey of the public lighting systems in the city of Comiso (RG) allowed to know and represents current and design performance figures such us installed power, luminance and illuminance levels in roads categories, electricity consumption, switching and dimming schedules. To do this many lighting simulations have been performed. Several scenarios have been proposed. The results obtained show that high improvements of the lighting quality are foreseeable together with large energy and economic saving. The proposed methodological approach can be applied in most of Sicilian and South Italy cities.
\end{abstract}

\section{KEYWORDS}

Street lighting, energy efficiency, sustainable energy action plan 


\section{INTRODUCTION}

Urban Electrical lighting consumption is very important in energy and economic balance for Italian Administration. The Italian research institute ENEA has developed a study about electric energy consumption for lighting which accounts for the $12 \%$ of total electricity demand. The same study has estimated that an annual achievable energy saving is about $30 \%$ [1].

The European Community provides several policy tools in order to achieve these savings. The first one is the "Covenant of Majors" (4400 partners of which 2100 Italian Municipalities). It is the main European movement involving local and regional authorities, voluntarily committing to increasing energy efficiency and use of renewable energy sources on their territories. By their commitment, Covenant signatories aim to meet and overcome the European Union 20\% CO2 reduction objective by 2020. The Sustainable Energy Action Plan (SEAP) is the main policy act that each Municipality adopts to reach this goal [2].

Provided that often, the Local Administrations don't know the actual consumption of systems, the first result of planning is to improve their knowledge about status and performances of their infrastructures. In Italy, the ENEA Guidelines are an useful support tool for efficient management of public lighting systems. The National Italian project Lumière identifies the Local Administration's needs about technical-economic factors for energy saving of lighting systems $[3,4]$. The identified needs are:

- to install more efficient and innovative systems;

- to lower energy consumption, costs and environmental impact;

- to decrease light pollution.

At the same time, some critical issues are identified in the first step of implementing energy saving actions. In fact in Italy, Energy Service Companies (ESCo) systems are often not suitable to implement these actions, because several of these are very big for small projects and the others haven't access to equity credit. Several examples of feasible energy strategies concerning smart lighting planning are today available in Italy. The Chiaramonte Municipality (PZ) has adopted actions able to grant annual energy savings about $687 \mathrm{MWh} / \mathrm{y}$ respect to $1732 \mathrm{MWh} / \mathrm{y}$ of the base case [5].

In San Giovanni in Marignano (RN), a high performance urban lighting system was installed. The efficiency improvement action started in 2003 and consisted in the installation of 2734 streetlights with proper cut-off system able to control the luminous flux and in the replacement of mercury-vapour lamps with high-pressure sodium lamps. A remote management system allows the point to point control streetlights for on/off switching, luminous flux dimming according to vehicular traffic intensity, time schedules and natural light contribution.

The achieved electricity saving is about $44.6 \%$ of which the $14 \%$ is due to luminaires replacement and $30 \%$ is due to remote management. The $\mathrm{CO}_{2}$ emissions saving is $158.500 \mathrm{~kg} / \mathrm{y}$ [6].

Worldwide, light emitting diode (LED) is emerging as the most energy efficient technology for lighting applications. Most of the existing applications focus on replacing existing streetlighting units with more energy efficient LED streetlighting system without any type of control to take advantage of its usage pattern. [7]

One interesting feature of LEDs is the ability to reduce their illumination level without any significant impact upon life and color [8,9]

Many studies have been made on methodology for indoor lighting control, e.g., methods for illumination control taking into account natural light [10,11], sensor network control for LED lighting system, and sensorless illumination control. Other publications discuss energy saving potentials of selected outdoor lamps [12] and their lighting control drivers [13,14]. 
Moreover, the lighting network can be utilised as a "platform" for the application of additional "smart" functions. The use of ICT technologies can be useful for many other tasks, such as monitoring environmental quality parameters like air quality (Ozone, $\mathrm{PM}_{10}$ ) controlling the vehicular traffic and many other purposes. [15-18].

Focussing on energy values of urban lighting systems refurbishments, several technological solutions, able to achieve relevant energy saving, are:

- On/off switching systems, with hourly on/off schedules in weekday and holidays, twilight switches and/or astronomical switches.

- Replacing lamps and/or luminaires by suitable optical system in order to reduce the lighting dissipation and to provide correct luminance levels on road surfaces, to avoid glare phenomena and to improve the Colour Rendering.

- Installing luminous flow regulators on switchboards. The installation of these devices achieves very important results in terms of energy saving. The reduction of absorbed power is obtained decreasing and stabilising the voltage during operation hours and in the night time according to the lighting needs; achievable savings are from $20 \%$ to $50 \%$, according to lamps type and other system conditions; furthermore by this way it is possible to obtain reductions of management and maintenance costs.

- Stabilizing and rephasing the system. The light sources require voltage not exceeding $5 \%$ of nominal value, in this way the voltage is set to $230 \mathrm{~V}$ in order to avoid decrease of the lamps life. Thanks to the reduction of the overvoltage time it is possible to obtain an additional saving of about $5-7 \%$.

- Adopting remote management systems. These devices provide real-time management of the energy demand, control and solving of system fails, economic costs control and ordinary/extraordinary maintenance management.

- Using Information and Communication Technologies. These devices allow the digital information transmission through electrical grid and/or radio waves. By the point-to-point control, it is possible to manage large data series (air quality measure, CCTV, energy consumption of public buildings and vehicular traffic monitoring), in order to improve the quantity and quality of information available for the citizen. The system could allow the "combination" of lighting infrastructures with many "smart services", in order to improve the performance and to reduce the costs.

\section{THE COMISO MUNICIPALITY: STATE OF THE ART OF THE PUBLIC LIGHTING SYSTEM AND ANALYSIS OF CONSUMPTIONS}

The lighting system in Comiso consists in 7809 poles, wall and pendant light systems, equipped with different typologies of luminaires and different power of lamps. A field survey of luminaires typology and suitability was completed. The stock of luminaires is made of lamp posts, street lighting systems, opal bubble glass systems, cylindrical opal glass systems, opal glass systems, pendant systems with aluminium lanterns and floodlight.

The study has shown that most luminaires and lamps are unfit to provide good lighting according to the Italian and European standards UNI EN 11248 and UNI 13201 [19-24]. These Standards give minimum requirements about luminance and illuminance values to be fulfilled in urban public areas and roads.

Most luminaires are unfit to control luminous flux:

- Cast Iron lamps posts, being without protection, generate glare phenomena. They are suggested only for small roads and in presence of high building;

- Opal bubble glass systems, when are without protection, create glare and the 50\% of luminous flux scatters upward or sideways. The opal material causes the $20 \%$ flux decrease; 
- Street light poles with cut-off system. The prismatic cup increases the uniformity of light but dissipates part of luminous flux. The cut-off system can decrease the dissipation, but it does not achieve energy saving, requiring system oversizing.

In the Figure 1 a selection of the most representative streets where lighting systems have the above mentioned luminaires is shown.

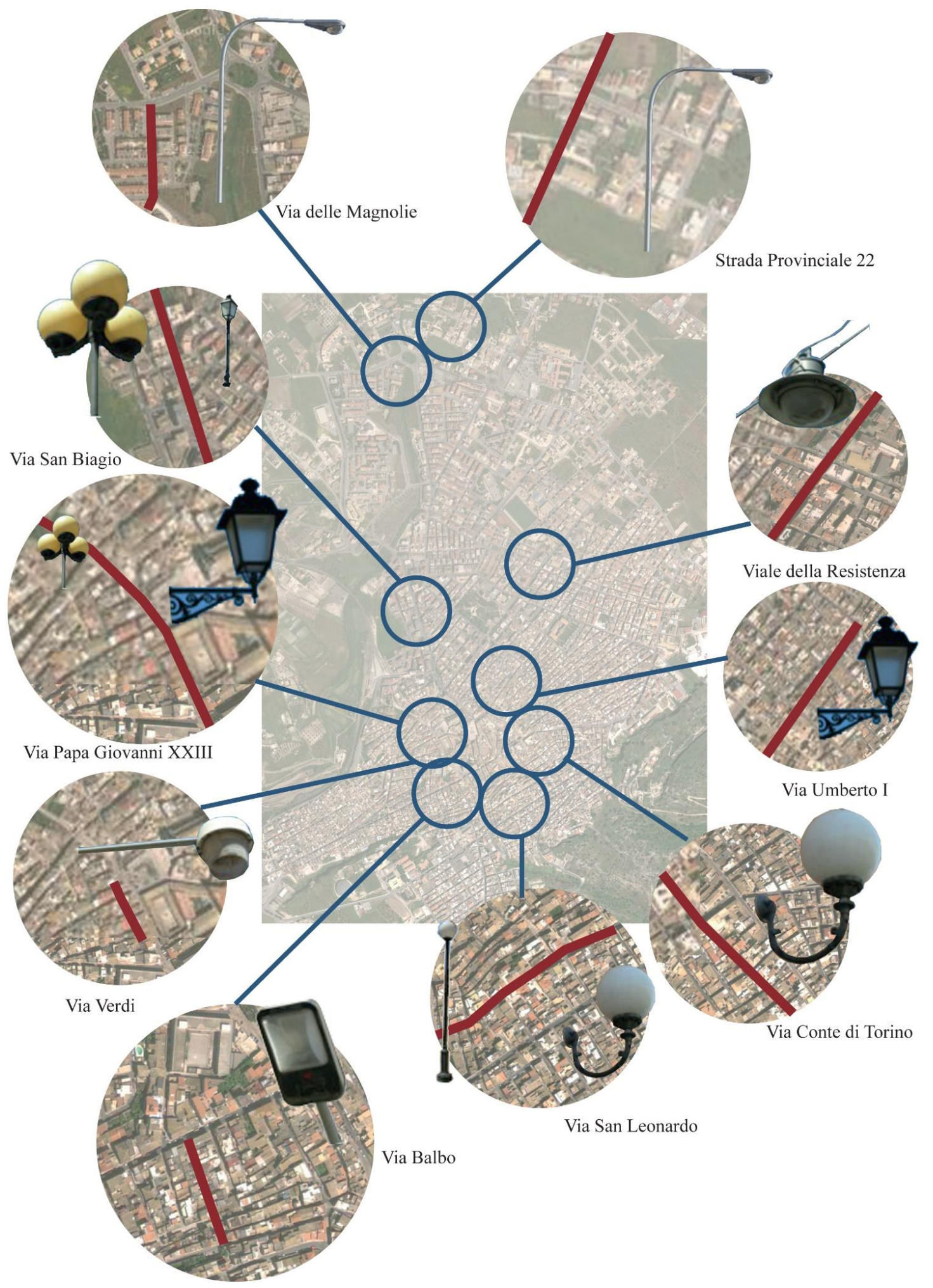

Figure 1. Comiso street light-system mapping. 
In the whole city, the luminaire distribution is composed by the following groups:

- 2858 Pole-top/wall street lighting systems with High Pressure Sodium lamps of $150 \mathrm{~W}$;

- 2280 Pole-top/wall street lighting systems with High Pressure Sodium lamps of 70 W;

- 433 Wall luminaire with opal crystal bubble glass with High Pressure Sodium lamps of 100W;

- 231 Pendant systems with aluminium lanterns with High Pressure Sodium lamps of 150W;

- 385 Pole-top/Wall systems with cylindrical opal glass luminaires High Pressure Sodium lamps of $70 \mathrm{~W}$;

- 457 Pole-top/wall street lighting systems High Pressure Sodium lamps of 100W;

- 201 Pole-top luminaires with opal crystal bubble glass High Pressure Sodium lamps of 100W;

- 58 Pendant systems with opal glass luminaires High Pressure Sodium lamps of 150W;

- 66 Pole-top luminaires with opal crystal bubble glass with Mercury Vapour lamps of 125W;

- 13 Wall luminaires with lantern with High Pressure Sodium lamps of 100W;

- 13 Wall luminaires with High Pressure Sodium lamps of 70W;

- 6 Other typologies with High Pressure Sodium lamps of 1000W;

- 60 Other typologies with High Pressure Sodium lamps of 250W;

- 154 Other typologies with High Pressure Sodium lamps of 150W;

- 68 Other typologies with High Pressure Sodium lamps of 400W;

- 5 Other typologies with Mixture light lamps of 160W;

- 140 Other typologies with High Pressure Sodium lamps of 100W;

- 48 Other typologies with Mercury Vapour lamps of 125W;

- 198 Other typologies with High Pressure Sodium lamps of 70W.

The lighting system is powered by $\mathrm{n} .107$ switchboards, that today are not equipped with voltage control or dimming system or automatic ignition.

Moreover, no data about phases balancing of single switchboard are available.

The consumption analysis, made by Comiso Municipality, show that the energy annual consumption, considering the on/off switching system (12 hours per day), is $\sim 4.036 \mathrm{MWh}$ (with emissions of $1598 \mathrm{tCO}_{2}$ /year) equal to $\sim 4800$ equivalent operating hours.

Compared to similar lighting systems, which value is $\sim 4200 \mathrm{~h}$, without control system management, this value is considerably high.

The annual average price of electricity is $0.14 € / \mathrm{kWh}$. The study showed that the annual costs of operation is $€ 563.041,92$ including $€ 70.000$ for maintenance costs.

\section{Development of energy saving strategies}

Several Scenarios for energy saving improvement are examined. The first one, Scenario 1, considers only the dimming of lamps, in order to verify the reduction of energy consumption based on an efficient management of operating hours. This dimming system is monitored at switchboard level.

Light control system installation, according to the ENEA Guidelines [1], reduces through a stepby-step management the luminous flux on the road surface. The steps are set by the seasonal and night/day switchboards input. In the Table 1 the dimming control setting are shown. 
Table 1. Control dimming system setting

\begin{tabular}{ccc}
\hline & Dimming control percentage a day & Equivalent Operating Hours per month \\
Winter season & {$[\%]$} & 93 \\
& 100 & 46.5 \\
Summer & 75 & 108.5 \\
season & 50 & 30 \\
& 100 & \\
& 75 & 45 \\
& 50 & 90 \\
\hline
\end{tabular}

The Scenario 2 considers only the current luminaires replacement with 7809 outdoor LED luminaires. The new luminaires are equipped by high efficient lamps (LED), as in many recent urban lighting refurbishment [7] and, in some case, with luminaires with fitting reflectors.

For this case several simulations have been performed, using the Dialux Software [24], for 9 sample roads representing the largest lamp/luminaries categories accounting for about the $90 \%$ of total installed power.

The new luminaires are characterized by proper photometric polar diagrams, which have been chosen with the aim of avoid dissipation of luminous flux. In particular, according to the mentioned Standard requirements, the luminaires can be replaced with the ones listed in the following table.

Table 2 - Replacement of lamps in the Scenario 2

\begin{tabular}{|c|c|c|c|c|c|}
\hline \multicolumn{4}{|c|}{ Base case Scenario } & \multicolumn{2}{|c|}{$\begin{array}{l}\text { Replacement proposed in Scenario } 2 \\
\text { (LED) }\end{array}$} \\
\hline \multicolumn{2}{|c|}{ Type of lamp } & W & $\begin{array}{c}\text { Total Installed Power for } \\
\text { each type of lamp } \\
{[\mathrm{kW}]}\end{array}$ & $\mathrm{W}$ & $\begin{array}{l}\text { Total Installed Power for } \\
\text { each type of lamp [kW] }\end{array}$ \\
\hline A & HPS & 150 & 428.7 & 90 & 257.2 \\
\hline B & HPS & 70 & 159.6 & 55 & 125.4 \\
\hline $\mathrm{C}$ & HPS & 100 & 43.3 & 41 & 17.7 \\
\hline $\mathrm{D}$ & HPS & 150 & 34.6 & 76 & 17.5 \\
\hline $\mathrm{E}$ & HPS & 70 & 26.9 & 48 & 18.4 \\
\hline $\mathrm{F}$ & HPS & 100 & 45.7 & 76 & 34.7 \\
\hline $\mathrm{G}$ & HPS & 100 & 20.1 & 56.3 & 11.3 \\
\hline $\mathrm{H}$ & HPS & 150 & 8.7 & 90 & 5.2 \\
\hline $\mathrm{I}$ & $\mathrm{HBO}$ & 125 & 8.2 & 56.3 & 3.7 \\
\hline $\mathrm{L}$ & HPS & 1000 & 6 & 600 & 3.6 \\
\hline M & HPS & 250 & 15 & 150 & 9 \\
\hline $\mathrm{N}$ & HPS & 150 & 23.1 & 90 & 13.8 \\
\hline $\mathrm{O}$ & HPS & 100 & 1.3 & 31.8 & 0.4 \\
\hline $\mathrm{P}$ & HPS & 400 & 27.2 & 240 & 16.3 \\
\hline Q & HPS & 70 & 0.9 & 41 & 0.5 \\
\hline $\mathrm{R}$ & $\mathrm{HBO}$ & 160 & 0.8 & 96 & 0.4 \\
\hline$S$ & HPS & 100 & 14 & 60 & 8.4 \\
\hline $\mathrm{T}$ & $\mathrm{HBO}$ & 125 & 6 & 75 & 3.6 \\
\hline $\mathrm{U}$ & HPS & 70 & 13.8 & 42 & 8.3 \\
\hline
\end{tabular}


Figure 2 shows for each group the amount of achievable reduction of installed power.

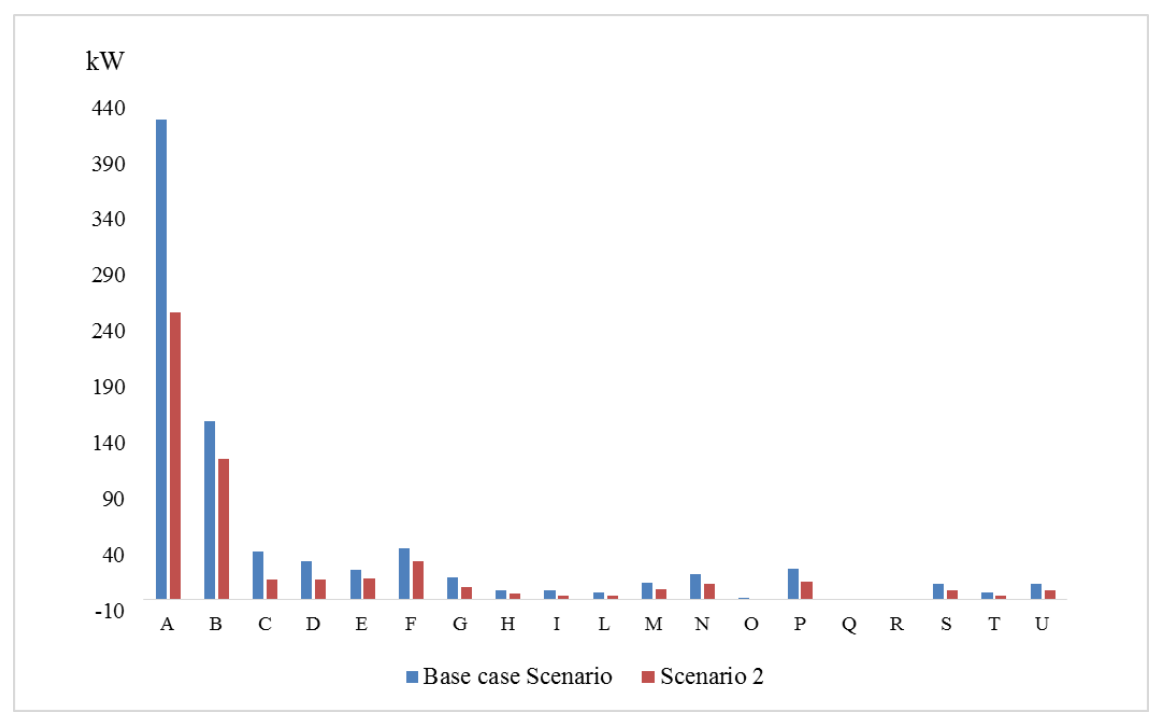

Figure 2. Reduction of installed power for each lamp/luminaries group

Total installed power by Scenario 2 is $555.9 \mathrm{~kW}$, which is considerably lower than the one of the base case Scenario $(884.1 \mathrm{~kW})$.

Results shown in in Table 2 and Figure 2 derive from detailed lighting design for the most representative 9 groups of roads. For each road a simulation has been performed to check the compliance to Standards UNI 11248 and UNI 13201. In most cases, without luminaires replacement, the Standard requirements were not respected. Only with the replaced luminaries they were achieved. The required Luminance values, Overall Uniformity (UO), Longitudinal uniformity (UL) and mean illuminance value on surface road $\left(E_{m}\right)$ parameters are shown for each Reference Lighting Category of the proposed road groups.

Table 3 - Replacement of lamps in the Scenario 2

\begin{tabular}{cccccc}
\hline Name of road & $\begin{array}{c}\text { Reference Lighting } \\
\text { Category } \\
\text { ME4b }\end{array}$ & $\begin{array}{c}\text { Luminance } \\
{\left[\mathrm{cd} / \mathrm{m}^{2}\right]}\end{array}$ & UO & UL & $\begin{array}{c}E_{\mathrm{m}} \\
{[\mathrm{lx}]}\end{array}$ \\
Strada Provinciale 22 & ME4b & 1.92 & 0.54 & 0.90 & - \\
Via Balbo & ME3c & 1.27 & 0.76 & 0.76 & - \\
Via Conte di Torino & ME3c & 1.05 & 0.59 & 0.84 & - \\
Via delle Magnolie & CE5 & & & & 8.22 \\
Via Papa Giovanni & CE5 & & & & 13.79 \\
XXIII & ME3c & 1.80 & 0.60 & 0.60 & - \\
Via San Biagio & ME3c & 1.23 & 0.44 & 0.82 & - \\
Via San Leonardo & ME4b & 1.33 & 0.73 & 0.86 & - \\
Via Umberto I & & & & & \\
Via Verdi & & & & & \\
\hline
\end{tabular}

The 3D false colour rendering presentations show that the luminous flux is not dissipated, but it is oriented on road surfaces. 
These project hypotheses have been studied in order to provide good visibility during night time, to guarantee road safety and physic and psychological comfort to users, to increase quality of life and to value aesthetically the city.

For some roads, such as Strada Provinciale 22 and via delle Magnolie, the luminaires have been replaced with one similar to the existing ones, but with lower lamp powers, because they were fit for that road. In other cases, such as via Balbo and via Umberto, the luminaires have been replaced with reflector better optics, but also characterized by a suitable design for old town centre reaching also the goal to make uniform the stock of luminaires in each road. $[25,26]$

Obviously, the different Reference Lighting Categories of roads, different reflectance of materials and the different luminaires and lamps installed in each roads gave opportunities to study different solutions, about power, reflector typology and luminaire design. Concerning the installed power, in some cases, such as for via Papa Giovanni case, it was possible to assessing values lower than actual values. So it was possible to downsize lamp powers and to obtain an energy saving.

Moreover, the colours of building are enhanced and not staggered, thanks to better CRI of LED lamps than High Pressure Sodium and Mercury Vapour lamps, as shown in real colour rendering presentation. [27]

As shown in Isolines (lx) presentations in Table 4, in most cases, such as via Umberto, the new installed luminaires provide a uniformity of light along road surfaces. Unlikely, in the remained cases the Standards requirements are achieved.

It must be highlighted that, in order to provide greater uniformity values, it would have been appropriate to study a new luminaires disposition, a shorter distances of the luminaires to each other and from the wall and sometime different heights. But, in order to limit final costs, current distances have been maintained.

Table 4. Scenario 2. Comparison between the lux Isolines on road surfaces
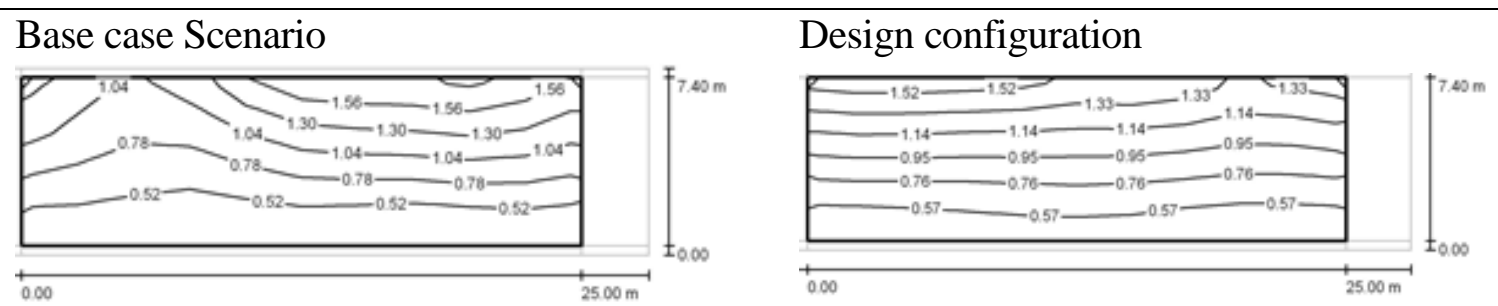

Strada Provinciale 22
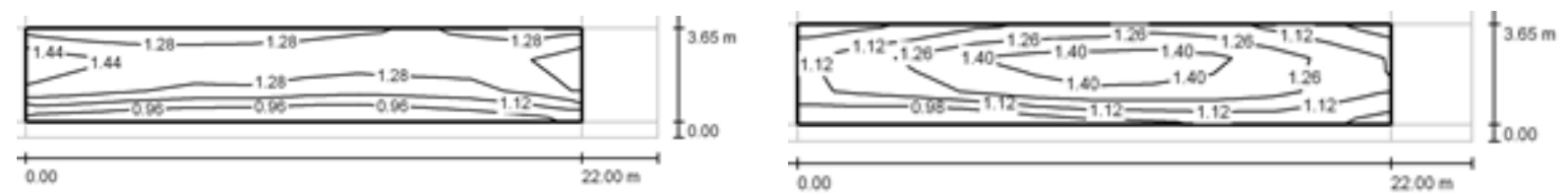

Via Balbo
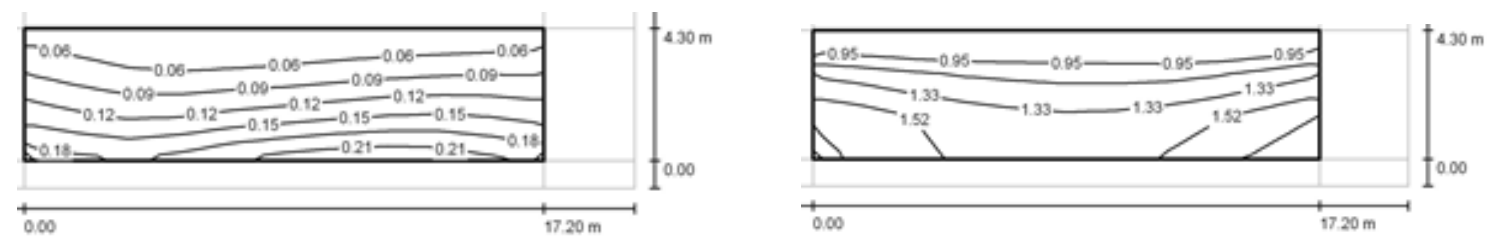

Via Conte di Torino 

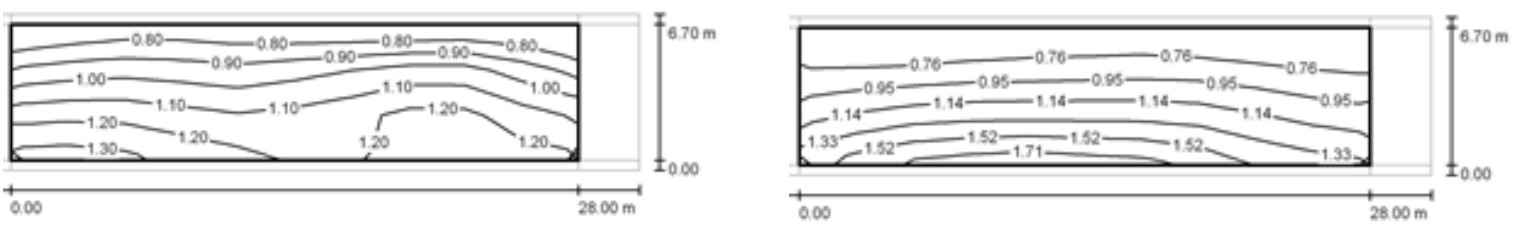

Via delle Magnolie
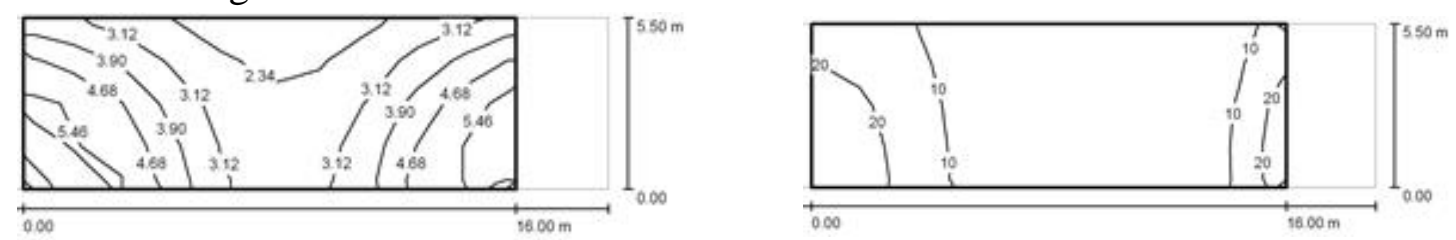

Via Papa Giovanni XXIII
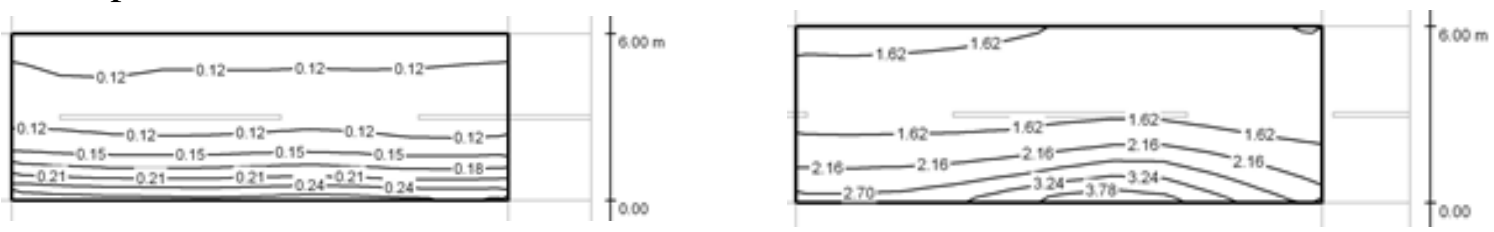

Via San Leonardo
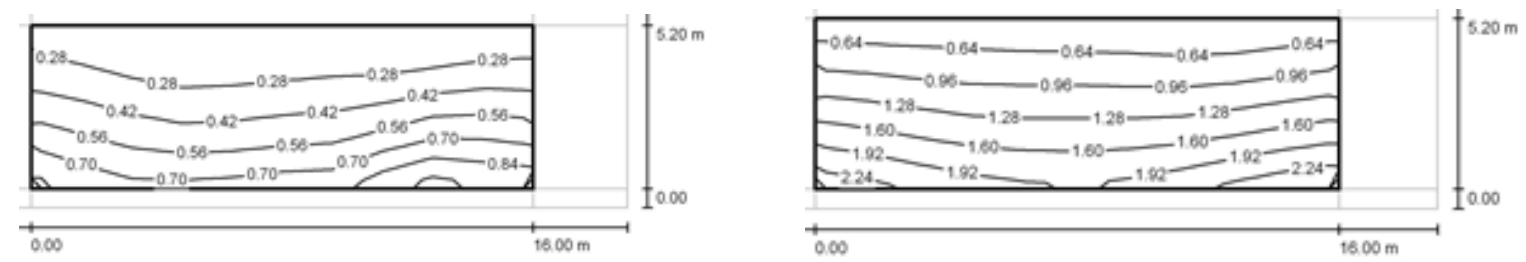

Via Umberto
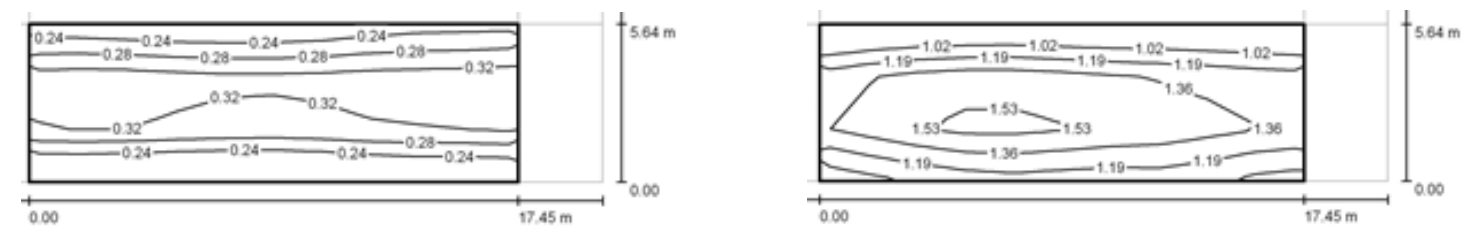

Via Verdi

In Figure 3 the 3D rendering in a false colour presentation and real colour rendering presentation are shown. 


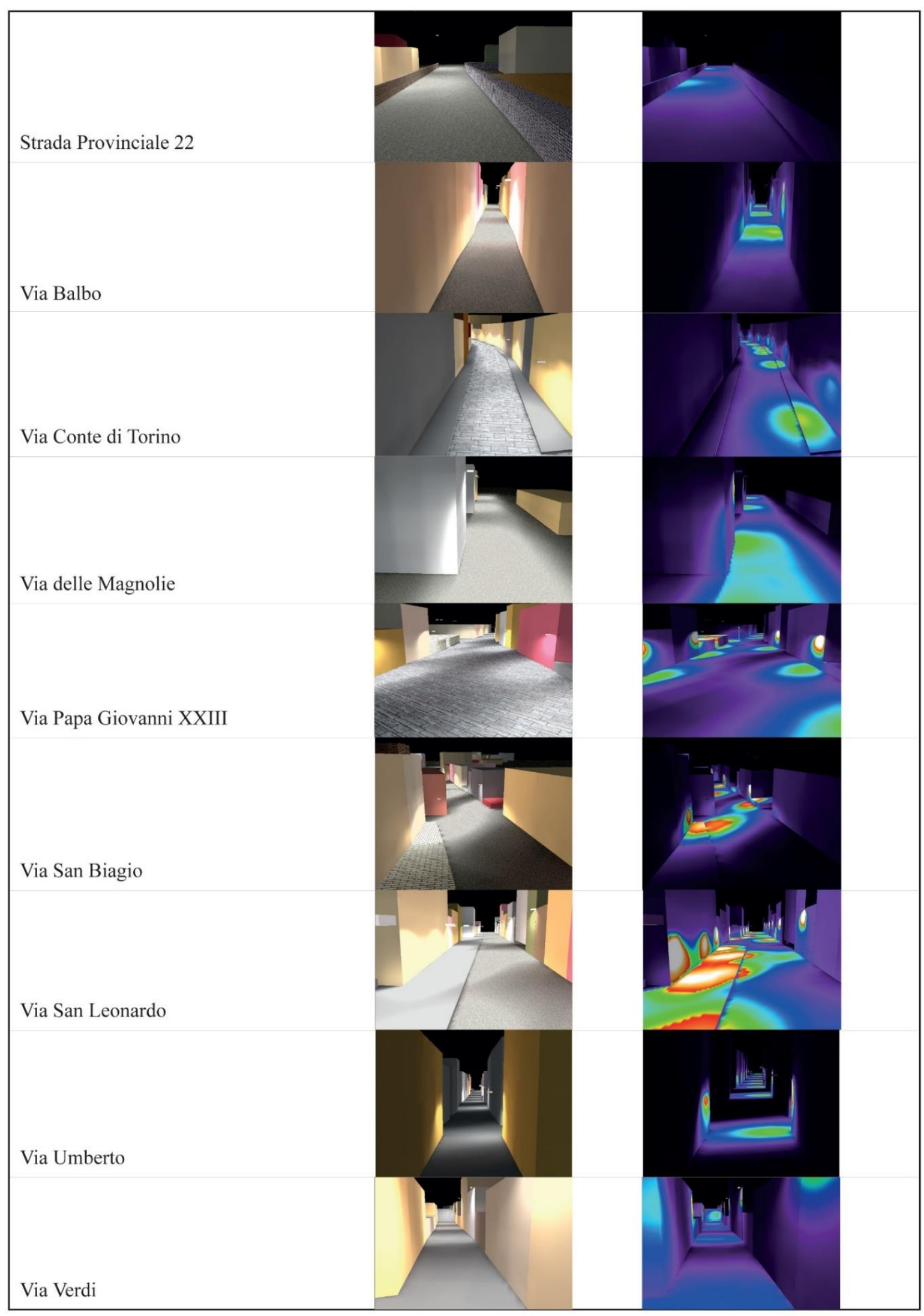

Figure 3. 3D rendering in a false colour presentation and real colour rendering presentation 
Figure 4 shows the results of simulations performed by Dialux Software in the proposed roads. The Scenario 3 represents the sum of Scenario 1 and Scenario 2 and it is more performing than Base case Scenario.

In Figure 5 yearly energy consumption are shown for each scenario. Above all, it is worth noting that in the summer season (from June to September) the dimming control system reduces significantly the energy consumption.

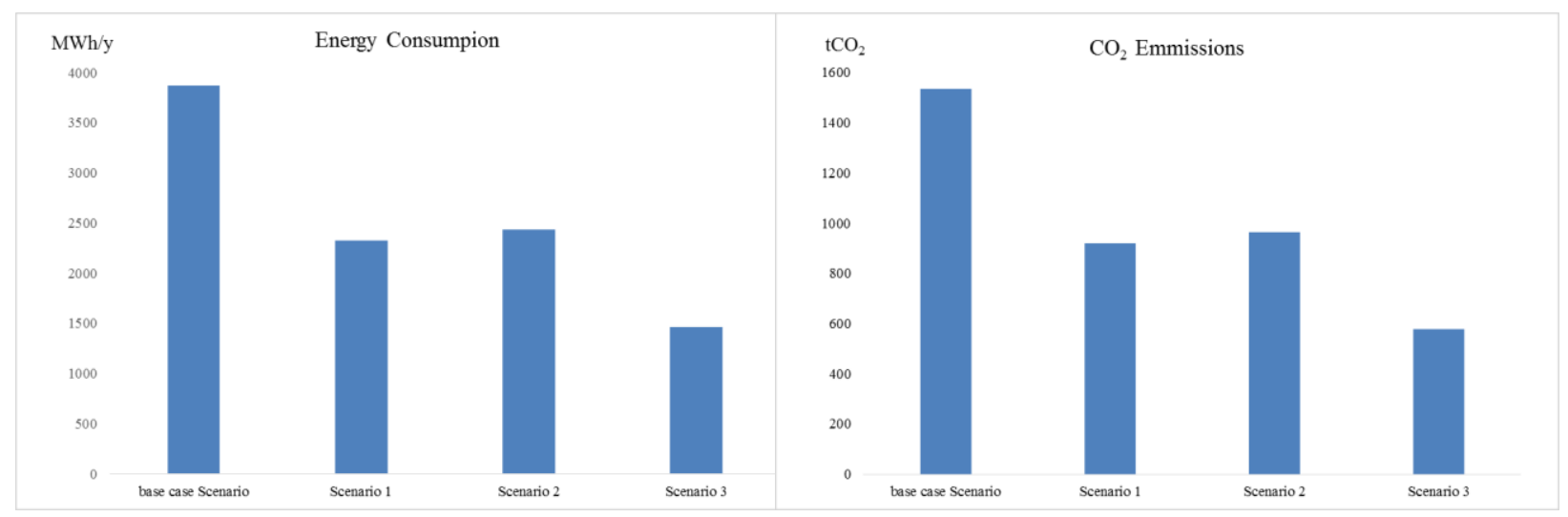

Figure. 4 Comparison between energy consumption and $\mathrm{CO}_{2}$ emissions in all proposed scenarios

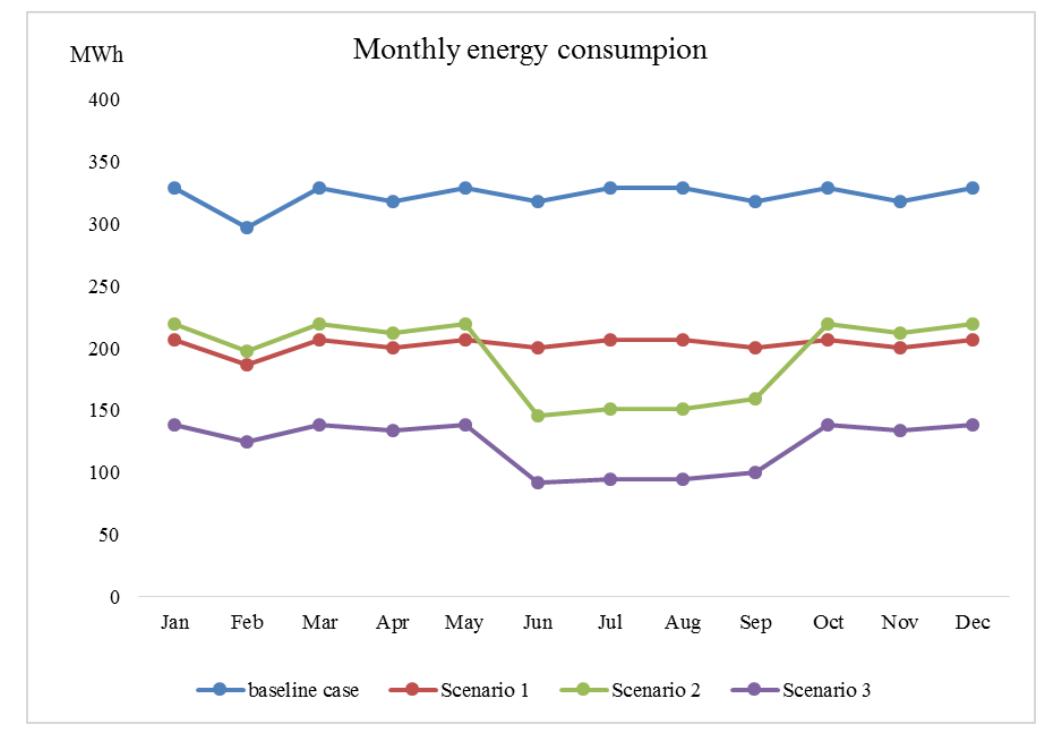

Figure 5. Monthly energy consumption in all proposed Scenarios

Table 5 summarises achievable energy and economic figures for each scenario: Capital investment, simple Payback Time, Energy Saving and avoided $\mathrm{CO}_{2}$ emissions are shown. In terms of energy saving Scenario 3 has the best performance with an energy saving of 2098.7 $\mathrm{MWh} / \mathrm{y}(\sim 52 \%)$ respect to base case Scenario.

Table 5. Comparison between three proposed scenarios

\begin{tabular}{cccccc}
\hline \multirow{3}{*}{ Scenario } & Capital & Energy & Economic & Simple Payback & $\mathrm{CO}_{2}$ \\
& Investment & saving & saving & Time & avoided \\
& $(€)$ & $(\mathrm{MWh} / \mathrm{y})$ & $(€ / \mathrm{y})$ & $($ years $)$ & $\left(\mathrm{tCO}_{2} / \mathrm{y}\right)$ \\
\hline
\end{tabular}




\begin{tabular}{cccccc}
\hline 1 & 1926200 & $\begin{array}{l}1009.0 \\
(-25 \%)\end{array}$ & 325532 & 8 & $\begin{array}{c}405.3 \\
(-25 \%)\end{array}$ \\
2 & 3123600 & $\begin{array}{l}1896.9 \\
(-47 \%)\end{array}$ & 340887 & 14 & $\begin{array}{c}745.1 \\
(-42 \%)\end{array}$ \\
& & & & 14 & 824.6 \\
3 & 5049800 & $\begin{array}{l}2098.7 \\
(-52 \%)\end{array}$ & 204688 & & $(-47 \%)$ \\
\hline
\end{tabular}

It can be noted that all the proposed investments are sustainable, and gives significant reductions of $\mathrm{CO}_{2}$ emissions and energy saving. The Scenario 3 proposes the best performance achieved by a significant reconfiguration of the system: a total replacement of light sources and the dimming control system are simulated. The Payback Time is acceptable, because the maintenance costs are evaluated, considering the longest life of the LED systems [28].

\section{CONCLUSION}

Urban lighting, predominantly street lighting, participates with high shares in global electricity consumption. This can be more evident in small cities where energy bills are often dominated by lighting service. Opportunities and benefits of refurbishment or re-design of lighting networks are often not clear to Public Administration unless many Policies have been set to foster this mismatch. In the framework of the UE initiative "Covenant of Majors", Municipalities have to develop a Sustainable Energy Action Plan (SEAP) as the main policy act to reach the objectives of energy saving. An analysis of a case study of a South Italy city is presented. The goal is to provide a method to assess savings, to select technologies options and to give a proof of achievable energy saving and $\mathrm{CO}_{2}$ emissions reduction. Projects must respect lighting standard requirements regarding safety and comfort in urban area.

The adoption of high efficient light sources such as LED allows to achieve good energy saving and contributes to have a greater colour rendering, bringing back a greater aspect to the city. Also new control and dimming strategies can gives excellent results.

For all the analysed scenarios, the results of an economic analysis are quite satisfactory, provided the LED cost is today relatively high. This factor is counterbalanced by the very high achievable savings in energy consumption and maintenance. By the way, a careful lighting design that considers roads typologies and their requirements can give not only economical improvements, but better conditions to citizens life.

In addition, a new lighting infrastructure can be the basis of a "smart network", a possible starting point toward the wider application in designing a "smart city".

\section{NOMENCLATURE}

$E_{m}$ average road surface illuminance (lx)

$\mathrm{L}_{\mathrm{m}}$ average road surface luminance (of a carriageway of a road) $\left(\mathrm{cd} / \mathrm{m}^{2}\right.$ )

UO Overall uniformity (of road surface luminance)

UI Longitudinal uniformity (of road surface luminance of a carriage way)

HPS High Pressure Sodium

HBO Mercury Lamp 


\section{REFERENCES}

1. Annunziato, M., Bucci, F., Meloni, C., Moretti, F., Pizzuti S., LINEE GUIDA: I fondamentali per una gestione efficiente degli impianti di pubblica illuminazione, Report ENEA - Agenzia nazionale per le nuove tecnologie, l'energia e lo sviluppo economico sostenibile, 2012.

2. http://www.covenantofmayors.eu.

3. Annunziato, M., Giuliani, G., Gozo, N., Honorati Consonni C., Frascone, A., Bucci, F., Lo Bue, B., Progetto Lumière: Efficienza Energetica nell'Illuminazione Pubblica. Percorso e metodologia di sviluppo, Report ENEA - Agenzia nazionale per le nuove tecnologie, l'energia e lo sviluppo economico sostenibile, 2012.

4. http://www.progettolumiere.enea.it/.

5. Sustainable Energy Action Plan, Comune di Chiaromonte (PZ), 2011.

6. Sustainable Energy Action Plan, Comune di San Giovanni in Marignano (RN), 2012.

7. Pipattanasomporn, M., Rahaman, S., Flory, I., Teklu, Y., Engineering design and assessment of a demand-sensitive LED street lighting system, Sustainable Energy Technologies and Assessment, Vol. 7, pp. 136-146, 2014.

8. NEMA. Guidelines on the application of dimming to high intensity discharge lamps, LSD 14-2002.

9. Ji Y., Wolsey R., Lighting answers: dimming systems for highintensity discharge lamps, Vol. 4, September 1994, ISSN: 1069-0050.

10. Pandharipande, A., Caicedo D., Daylight integrated illumination control of LED systems based on enhanced presence sensing, Energy Build, Vol. 43, pp 944-950, 2011.

11.Soori, P.K., Vishwas, M., Lighting control strategy for energy efficient office lighting system design, Energy Build, Vol. 66, pp 329-337, 2013.

12.Wei, Y., Hui S.Y.R., Chung H.S-H., Energy saving of large-scale high-intensity discharge lamp lighting networks using a central reactive power control system. IEEE Trans Ind Electron, Vol. 56, pp 3069-3078, 2009.

13. Chiu, H-J., Lo Y-K., Chen J-T, Cheng S-J, Lin C-Y, Mou S-C, A high-efficiency dimmable LED driver for low-power lighting applications. IEEE Trans Ind Electron, Vol.57, pp 735743, 2010.

14. Gacio, D., Alonso, J.M., Garcia, J., Campa, L., Crespo M.J., Rico-Secades, M., PWM series dimming for slow-dynamics HPF LED drivers: the high-frequency approach. IEEE Trans Ind Electron, Vol. 59, pp 1717-1727, 2012.

15.Menga, R., Grattieri, W., Linee Guida Operative per la realizzazione di impianti di Pubblica illuminazione, SSE - Sviluppo dei Sistemi Elettrici, CESI Report, Feb 2009.

16.Marsal-Llacuna M.L. Colomer-Llinàs J., Meléndez-Frigola J., Lessons in urban monitoring taken from sustainable and livable cities to better address the Smart Cities initiative, Journal of Technological Forecasting \& Social Change, Elsevier, in press.

17.http://epp.eurostat.ec.europa.eu/portal/page/portal/region_cities/city_urban.

18.UNI 11248:2012, Light and lighting, Road lighting - Selection of lighting classes.

19.EC 1-2013 UNI 11248:2012, Light and lighting, Road lighting - Selection of lighting classes.

20.EN 13201-2:2004, Light and lighting, Road lighting - Part 2: Performance requirements.

21.EN 13201-3:2004, Light and lighting, Road lighting - Part 3: Calculation of performance.

22.EC 1-2007 UNI EN 13201-3:2004, Light and lighting, Road lighting - Part 3: Calculation of performance.

23.EN 13201-4:2004, Light and lighting, Road lighting - Part 4: Methods of measuring lighting performance.

24.http://www.dial.de/DIAL/it/dialux.html

25.Kocet, V., Contemporary urban lighting and lighting of old city centres and historic sites, Green building Council of Croatia, Dubrovnik, April 6-8, 2011. 
26.Kostic, M., Djokic, L., Recommendations for energy efficient and visually acceptable street lighting, Energy, Vol. 34, pp 1565-1572, 2009.

27.The Institution of Lighting Engineers. The outdoor lighting guide. Taylor \& Francis; 2005, ISBN 0415370078.

28.Coureaux, M., Manzano, E., The energy impact of luminaire depreciation on urban lighting, Energy for Sustainable Development, Vol. 17, pp. 357-262, 2013. 